\title{
Rural Revitalization Boosts Meigu's Agricultural and Rural Economic Development
}

\author{
Dirierzhe \\ College of Urban Planning and Architecture, Southwest Minzu University, Chengdu, China \\ Email: 853137573@qq.com
}

How to cite this paper: Dirierzhe (2021) Rural Revitalization Boosts Meigu's Agricultural and Rural Economic Development. Open Access Library Journal, 8: e7634. https://doi.org/10.4236/oalib.1107634

Received: June 10, 2021

Accepted: July 10, 2021

Published: July 13, 2021

Copyright $\odot 2021$ by author(s) and Open Access Library Inc.

This work is licensed under the Creative Commons Attribution International License (CC BY 4.0).

http://creativecommons.org/licenses/by/4.0/

\begin{abstract}
The country revitalization strategy is the party's 19th in the era of the new rural construction and management of an important strategy to implement the strategy of rejuvenating the country, to promote the rural industries, promote the revitalization of rural talents, promote the revitalization of rural culture, $\mathrm{Xi}$ Jinping, general secretary from the height of the strategic and global rural revitalization planning as a whole, science push forward. The purpose of this paper is to contrast rural revitalization, meaning to improve the Meigu in existing in the construction of rural talents and promote the use of science and technology, industries and increasing farmers' income, the difficulties of the rural modernization construction, the bottleneck, in order to solve the current "three rural" development of differentiation, uneven, lagging problem provides new ideas, new methods and new requirements, and to better consolidate and deepen the crucial results provides strategic poverty Guidance. The result of this study is the rural revitalization strategy is in line with the development requirements of the country and society.
\end{abstract}

\section{Subject Areas \\ Development Economics}

\section{Keywords}

Rural Revitalization, Agricultural Industry, Development

\section{The Significance of Implementing the Rural Revitalization Strategy}

In the new era, the main problem facing society is that unbalanced and inade- 
quate social development cannot meet the people's needs for a better life, and agricultural and rural problems are the main manifestation of unbalanced and inadequate development [1]. We need to give full play to the basic role of agriculture and rural areas in economic development and effectively respond to the major social contradictions in the new era. Through the in-depth implementation of the rural revitalization strategy, the speed of agricultural and rural economic development can be accelerated, the quality of development can be improved, and farmers' needs for a better life can be met. At the present stage, various problems in agricultural and rural development have caused certain constraints on the overall development of the country and society. Only by continuously optimizing the level of agricultural modernization and strengthening the construction of rural modernization can the overall level of national modernization be promoted [2]. Therefore, it is necessary to carry out rural revitalization, vigorously develop agricultural and rural economy, and promote the smooth realization of the strategic goal of modernization.

\section{The General Situation of the Meigu}

Meigu County is located in the heart of Liangshan Yi Autonomous Prefecture, southwest of Sichuan Province. The county has jurisdiction over 36 townships (towns), 292 villages, and 272 poverty-stricken villages. By 2018, 135 poverty-stricken villages had been eliminated. In 2018, 28,015 poor people from 5851 households had achieved poverty reduction, and the poverty incidence rate had dropped to 18.66 percent. It is estimated that by the end of 2020, Meigu County will have achieved a comprehensive poverty alleviation and achieve a well-off society. The county is dominated by the Yi ethnic group, whose population accounts for $98 \%$ of the total population of the county. Due to the influence of geographical, historical, environmental and other factors, Meigu belongs to an area of deep poverty in China, and its poverty is deep and covers a large area. Through years of efforts, the eradication of poverty in Meigu has achieved results. Although after a long, hard Meigu to a poor old face, but relative to the other brother county, whether the economy, society, education development, such as per capita income is far behind the brothers county, for the future in Meigu county rural revitalization strategy under the background of new era of development, its development path according to its own agricultural production in recent years. The characteristics of industrial structure are mainly developing agricultural products, planting industry, animal husbandry, and traditional Chinese medicine etc.

\section{The Restrictive Factors of Meigu's Rural Economy}

In recent years, there are still a lot of problems in the development of Meigu itself, which can be divided into four categories [3]. Farmers' ideas are conservative, infrastructure is weak, industrial chain is short, talent is lacking. 


\subsection{The Concept of Farmers}

For a long time, farmers have been living in remote transportation areas, relatively isolated geographical environment, poor environment, and relatively backward cultural and technological quality of labor force. They are still accustomed to wide planting and low yield and traditional planting and breeding mode, with low willingness to accept new technologies and new varieties, and low enthusiasm for land transfer. Secondly, the traditional rural areas have long formed a busy and leisure farming lifestyle, without innovative farming channels, technology and means, the lack of innovative thinking concepts, courage. Thirdly, since the fight against poverty, the national policies and measures to help the poor areas have had a qualitative impact on the life of the population in the poor areas, and some of them will have a negative impact. The state policy welfare is much, it is hard to avoid some people sit and wait for the state policy to supply, compete for the poor households, the existence of "bask in the sun and so on to send well-off" and other phenomena.

\subsection{Weak Agricultural Infrastructure}

In order to vigorously develop the agricultural and rural economy, Meigu has vigorously carried out the construction of rural infrastructure, but there are still many problems in the development of agricultural mechanization and the construction of irrigation and water conservancy facilities. The economy in high mountain areas is relatively backward, and the agricultural facilities are old, and various new machines and technologies have not been widely used in agricultural production practice, leading to low economic benefits in agricultural production. At the same time, there is the lack of sound infrastructure investment. It is still mainly funded by the government, and there is no social fund investment mechanism and lack of corresponding incentive policies. Lack of capital will hamper agricultural infrastructure.

\subsection{Shortcomings of the Industrial Chain}

Agricultural industrialization is still in the primary stage of development [4]. The industrial structure is fuzzy; the scale effect of characteristic industry is not outstanding. Most of them are still dominated by small-scale peasant economy, and the situation of "small, scattered and weak" is prominent. The formation of capital in agricultural industry is slow, and the structure of some capital elements is unreasonable. Traditional advantageous industries are not consciously controlled by economic laws, can only carry out habitual cultivation, extensive production management, insufficient scale management, small quantity of characteristic agricultural products, low degree of marketization. Second, the lack of operating subject demonstration drive, characteristic agricultural and animal husbandry products processing is insufficient, processing structure is relatively single, low added value of products. Third, the characteristic agricultural products brand construction and market development is insufficient, lack of regional 
brands and enterprise brands with strong influence.

\subsection{Insufficient Talent Reserve}

In the process of promoting industrial development in some villages, there are some problems such as unclear professional direction of talent attraction and recruitment, insufficient supporting welfare policies, obvious short-term sexual behaviors on the job, etc., and the merger of rural agricultural technology extension organizations has resulted in an embarrassing situation of "broken lines, scattered staff and broken networks". The ranks of agricultural technicians are unstable.

\section{Case Study and the Promotion Effect of Rural Revitalization Strategy on Agricultural and Rural Economic Development}

\subsection{The Successful Experience of County}

The county of Aba prefecture, a minority area around chengdu, has formed a large-scale, organized and standardized breeding industry and a tourism industry with mature lines, perfect service system and perfect policies [5].

1) The industrial scale is basically stable

Since the establishment of chengdu "autumn light" vegetable third-line base in the 1980s, the governments at all levels of li county have made full use of the local three-dimensional climate resources and vigorously developed the production of alpine off-season superior vegetables, which are cultivated in all townships and towns of the county. Currently, a large vegetable production gradually formed the scale, variety by the past simple development to such as cabbage, lettuce, hot pepper, celery, many kinds of pattern match the development of the industry, has realized the hit lixian mountain anti-season vegetables of high quality, high efficiency, high yield, present a huge potential for development, including Chinese cabbage is one of the largest vegetable species, a large scale and output of vegetable total income $50.5 \%$.

2) The regional layout has gradually taken shape

In the development of vegetable industry in Li County, the industry is divided regionally according to the altitude. From 1800 to $3000 \mathrm{~m}$, leaf vegetable varieties dominated by Chinese cabbage and lettuce were planted. From 1400 to 2700 $\mathrm{m}$, cabbage, radish, pepper, lettuce, cauliflower, onion, vegetable potato, pea and other vegetable varieties are mainly planted. Under $2000 \mathrm{~m}$, tomato, pepper, celery, suanmiao, chives, cucumber, bitter gourd and other fine vegetable varieties are mainly planted, and fruit tree + vegetable interplanting mode is mostly adopted. Under the mature development system, a regional pattern of vegetable industry with Chinese cabbage and lettuce as the leading and fine vegetables as the auxiliary has been gradually formed.

3) Relying on superior geographical location

In the distribution and development of tourism resources in Li County, three 
rural tourism development models have been created, namely, relying on scenic spots, relying on folk customs and integrating scenic villages. Through the radiation circle of mature scenic spots, neighboring villages can assume part of the function of serving the streets. Relying on the advantages of folk customs, to create a unique architectural style and catering culture, $B \& B$ produces an ideal place to experience folk customs and $B \& B$. The integration of Jingcun provides tourists with multiple choice routes, meeting the needs of tourists for sightseeing, eating, accommodation, and transportation and so on, making tourists stay today, tomorrow and the day after tomorrow as the purpose.

\subsection{The Promoting Effect of Rural Revitalization Strategy on Agricultural and Rural Economic Development}

1) Accelerate the pace of agricultural transformation and upgrading, and build a characteristic agricultural development system

The featured products in Meigu include potato, plateau vegetables, black goat, rock eagle chicken, plateau Tartary buckwheat, high-quality Chinese prickly ash and other agricultural and animal husbandry products. We make full use of the local advantages to expand and strengthen the featured agricultural products and actively develop the remaining competitive industries. In the business model, we can adopt the mode of "combination of planting and breeding and ecological cycle", and promote the organized, standardized and large-scale breeding of black goat and rock eagle chicken with the core of the breeding and promotion of fine varieties with characteristics. And exerting comparative advantages, such as breed of climate, with an emphasis on potato, plateau buckwheat contour elevation, accelerate the standardization of plateau in the wrong season vegetables, grain, make plant production areas to optimize rural, adjust measures to local conditions, sets up the agriculture modernization thought, by reasonable planning and design, expand production efficiency to the greatest extent.

2) Improve farmland infrastructure construction to improve quality and increase value

We actively sought special subsidies for the construction of small irrigation and water conservancy projects at the central and provincial levels, and built small drought-resistant and water-storage projects. We will expand water-saving irrigation technologies and facilities, strengthen farmland protection and soil improvement, support farmers in burning straw to increase soil organic fertility on the premise of ensuring safety, accelerate the introduction of advanced and suitable agricultural machinery, and improve preferential policies on taxes and fees for agricultural mechanization.

3) Exploit the potential of agricultural products and strengthen brand building

According to the working idea of "based on a resource advantage, around an industrial chain, focus on a trademark registration, and drive a group of characteristic brands", focus on the trademark registration of agricultural and sideline products, make good use of the regional brand of "Meigu", and play the "green 
card", "ecological card" and "wrong season card". For local agricultural products, formulate specific support measures, do a good job in trademark registration application, and uniformly carry out online marketing work such as packaging design and production of online marketing products and brand planning.

4) Base on local environmental advantages and tap the potential of tourism resources

Accelerate the organic integration with the new urbanization and the construction of beautiful countryside, and combine the eating habits of the Yi people to create and launch a tourism operation route combining accommodation and food. Accelerate the organic integration of tourist holiday products with points, lines and surfaces, strengthen the construction and protection of local characteristic landscape buildings, ecological vegetation, villages and pastoral areas along the routes, and create a pleasant tourism holiday environment. We should attach importance to industrial cultural deposits, ecological protection and ecological restoration, the construction of linear tourism routes, the overall planning and innovation of investment models for tourism marketing, and accelerate the introduction of funds for the development of tourism and related industries.

5) Improve the talent attraction system and guarantee the supporting capacity of talents

We will implement a targeted training mechanism for college graduates. For the special talents that are urgently needed in the stage of development, the flexible talent policy is carried out to reduce the cost of "cultivating talents" and improve the efficiency of "using talents". From the perspective of policy, the salary, welfare and position of talents should be encouraged in the whole process to attract migrant workers to return home and start businesses. Implement the system of connecting Party and government leaders with outstanding talents, improve the skills and knowledge of traditional agricultural technicians, encourage and guide agricultural technicians to learn new technologies, accelerate the reform and construction of rural extension stations, introduce new agricultural technicians, and optimize the structure of rural agricultural technicians; focusing on the development needs of leading agricultural industries in Meigu County, cultivating leading talents of grass-roots agricultural technology extension.

\section{Conclusion}

To sum up, the rural revitalization strategy is in line with the development requirements of the country and society. By vigorously developing agricultural and rural economy, the goal of modernizing China into a socialist country can be successfully realized. Meigu should combine the influencing factors of agricultural and rural economic development at the present stage, formulate perfect solutions and optimization countermeasures, accelerate the pace of transformation and upgrading of agricultural structure, vigorously develop new rural industries, improve the quality of agricultural and rural economic development, and enhance the implementation effect of rural revitalization strategy. The agri- 
cultural industry should be promoted from "small dispersion and weakness" to "intensification, scale and modernization", that is, from weakness to strength. We should take a good road of rural revitalization; build a new era of Meigus, and build of new agriculture, rural areas and farmers.

\section{Conflicts of Interest}

The author declares no conflicts of interest.

\section{References}

[1] Chang, R., Jin, K.H. and Li, Y. (2019) Exploring the Path of Agricultural Industry Capital Formation in Deep Poverty Areas to Promote Rural Revitalization-Based on Industrial Development Perspective in Poverty-stricken Villages in Liangshan. Southwest Finance, 40, 44-54.

[2] Wu, Q., Liu, Y.L., Chen, C.Y. and Lin, Z.Y. (2020) Study on Development Strategy of Characteristic Agricultural Industry in Deep Poverty-Stricken Areas of Sichuan -A Case Study of Butuo County, Liangshan Yi Autonomous Prefecture. Sichuan Agricultural Science and Technology, 50, 61-64.

[3] Han, C.f. (2017) Study, Publicize and Implement the Spirit of the 19th National Congress of the Communist Party of China and Vigorously Implement the Strategy of Rural Revitalization. Chinese Agricultural Accounting, 27, 54-55.

[4] Gao, Y.C. (2017) Exclusive Interview with Minister of Agriculture Han Changfu on the Major Deployments of Rural Revitalization Deciding to Win a Comprehensive Well-Off. People's Daily, 2017-11-16.

[5] Chen, X.W. (2018) Implementing Rural Revitalization Strategy and Promoting Agricultural and Rural Modernization. China Agricultural University Journal of Social Sciences Edition, 35, 5-12. 